\title{
Improving the Outcomes of Modified Manual Small Incision Cataract Surgery Using Clinical Audit
}

\author{
Muhammad Ifraheem Khan ${ }^{1}$, Saba Ali Arif ${ }^{2}$, Muhammad Raja ${ }^{3}$, Sheikh ljaz ${ }^{4}$, Muhammad Saeed Khan ${ }^{5}$ \\ ${ }^{1}$ Layton Rehmatullah Benevolent Trust Free Eye Hospital ${ }^{2}$ Pakistan Institute of Medical Sciences, ${ }^{3}$ James Paget \\ University Hospitals NHS Foundation Trust, ${ }^{4}$ East Surrey Hospital Red Hill. UK \\ ${ }^{5}$ Layton Rahmatulla Benevolent Trust
}

\begin{abstract}
Purpose: To use clinical audit in improving the outcomes of manual small incision cataract surgery technique

Study Design: Clinical audit.

Place and Duration: Layton Rehmatullah Benevolent Trust Eye hospital Karachi, from September 2019 to December 2019.

Methods: Two hundred patients who had undergone Manual Small Incision Cataract surgery were selected. Cases with traumatic cataract, weak zonules, pseudoexfoliation, and more than 1 diopter difference in keratometric readings, corneal and retinal pathologies were excluded. Surgical complications and visual outcomes were recorded on the 7th postoperative day. Refractive data was recorded from subjective refraction. Data was analyzed by University Hospital Bristol formula. Standards were set using international literature. Deficiencies were noted and technique was modified to improve the outcome. The audit was repeated after 2 months to see whether modifications had improved the outcome.
\end{abstract}

Results: In the first audit, posterior capsular rupture rate was $1 \%$, corrected visual acuity of $6 / 12$ or better was achieved in $85.36 \%$ and surgically induced cylinder of less than 2 DC was achieved in $75.60 \%$ of the patients. In the second audit all standards were achieved. Posterior capsular rupture did not occur. Corrected visual acuity of $6 / 12$ or better was achieved in $90.50 \%$ and induced cylinder of less than 2 DC was achieved in $87.05 \%$ of the patients.

Conclusion: Clinical audit of the surgical procedures is a good technique in improving the outcomes of manual small incision cataract surgery.

Key Words: Cataract extraction, clinical audit, posterior capsular rupture, astigmatism, visual acuity.

How to Cite this Article: Khan IM, Arif SA, Raja M, ljaz S, Khan MS. Improving the Outcomes of Modified Manual Small Incision Cataract Surgery Using Clinical Audit. Pak J Ophthalmol. 2021, 37 (3): 322-326.

Doi: $10.36351 /$ pjo.v37i3.1234

\section{INTRODUCTION}

The most common type cataract formation is the senile cataract which results from different biochemical and structural alterations in lens with advancing age. ${ }^{1}$

Correspondence: Muhammad Ifraheem Khan

Layton Rehmatullah Benevolent Trust Free Eye Hospital

Email: ifraheem.khan@yahoo.com

Received: February 25, 2021

Accepted: April 28, 2021
Although exact pathogenesis is unclear, as the person ages, lens proteins breakdown and form clumps of high molecular weight materials which opacify and affect the visual quality. ${ }^{2}$ Other causes include trauma, drugs, metabolic disorders, radiation and congenital. Cataract is the second most common cause (65.2 million people) of decreased vision and the most common cause of treatable blindness worldwide. ${ }^{3}$ Efforts are continuously made to improve the outcomes of cataract surgery for which new techniques are introduced and old are improvised. A cost effective alternative to phacoemulsification is Manual Small 
Incision Cataract Surgery (MSICS) which has comparable best corrected visual acuity to phacoemulsification, but can produce higher induced astigmatism. Phacoemulsification is gold standard for cataract surgery because of small incision size, faster visual recovery/rehabilitation and minimum surgically induced astigmatism, but is not available in all parts of the world because of high cost, longer learning curve and technical expertise. ${ }^{4}$ Extra capsular cataract extraction (ECCE) is less favored because it requires large incision, suture closure of the wound and slow rehabilitation. $^{5}$

To judge the outcomes of a surgical procedure, clinical audit is a very effective tool in improving the quality. ${ }^{6}$ Generally speaking, there are 2 ways of audit. Firstly to join an already organized audit and secondly to setup an audit yourself. ${ }^{7}$

We used clinical audit cycle in this study to improve our surgical outcomes in terms of reducing posterior capsular rupture rate and visual status. We compared our results with internationally accepted standards.

\section{METHODS}

The first audit was done between $21^{\text {st }}$ September 2019 and 30 September 2019. We examined 100 consecutive surgeries of MSICS in July 2019 by one surgeon in Layton Rehmatullah Benevolent Trust Eye hospital Karachi. Cases with traumatic cataract, weak zonules, pseudoexfoliation, and more than 1 diopter difference in keratometric readings, corneal and retinal pathologies were excluded.

Following standards were set (to compare the outcome) after reviewing the literature; ${ }^{7,8,9,10}$

\begin{tabular}{clc}
\hline SN & Outcome & Proportion \\
\hline 1. & Posterior capsular rupture with vitreous loss & $1.4 \%$ \\
2. & $\begin{array}{l}\text { Over all best corrected Snellen visual acuity } \\
\text { of 6/12 or better }\end{array}$ & $89.2 \%$ \\
3. & $\begin{array}{l}\text { Surgically induced astigmatism of 2DC or } \\
\text { less }\end{array}$ & $85 \%$ \\
\hline
\end{tabular}

MSICS was performed as follow; a straight, partial thickness incision was made about $1.5 \mathrm{~mm}$ posterior to the limbus in conjunctiva and sclera superiorly centering at $12 \mathrm{o}$ clock position. A tunnel entry of about $2.5 \mathrm{~mm}$ long was made into the anterior chamber with $3.2 \mathrm{~mm}$ keratome. After capsulorhexis (about
$6 \mathrm{~mm}), 3.2 \mathrm{~mm}$ wide tunnel was extended by passing a $5.2 \mathrm{~mm}$ keratome through it. Intraocular PMMA lens was implanted after nucleus delivery with wire vectus and lens matter removal with irrigation aspiration cannula.

Data was obtained from electronic patient record, patient files, surgical complication logbook, postoperative refraction and visual acuity (7th postoperative day) logbook. Refractive data was recorded as subjective refraction (not keratometric readings) of patients on first follow up (1 week after surgery).Recorded data was analyzed according to the formula developed by audit department of University Hospital Bristol ${ }^{11}$ and results were compared with standards. After analysis, our results were presented in hospital meeting. Deficiencies (detailed in table $1 \& 2$ ) were noted and discussed. After discussion, it was planned to apply some modification to the technique and do another audit after 2 months to see if modifications applied have improved the outcome. Following modifications were made; main incision was moved from superior to superotemporal location and two side ports of about $2 \mathrm{~mm}$ wide were made about 3 clock hours away from the center of main incision in clear cornea on each side to neutralize the astigmatism caused by the main incision. All steps of the main incision were completed with $3.2 \mathrm{~mm}$ keratome (5.2mm keratome was not used). Steps of the surgery are shown in figure 1 and 2.

The second audit was done in December 2019 in which 100 surgeries done between 01/11/2019 and 21/11/2019were evaluated to see whether applied modifications had improved the outcome. Data collection and methods of analysis were same as for the first audit and results were compared with set standards (Table 1 and 2).

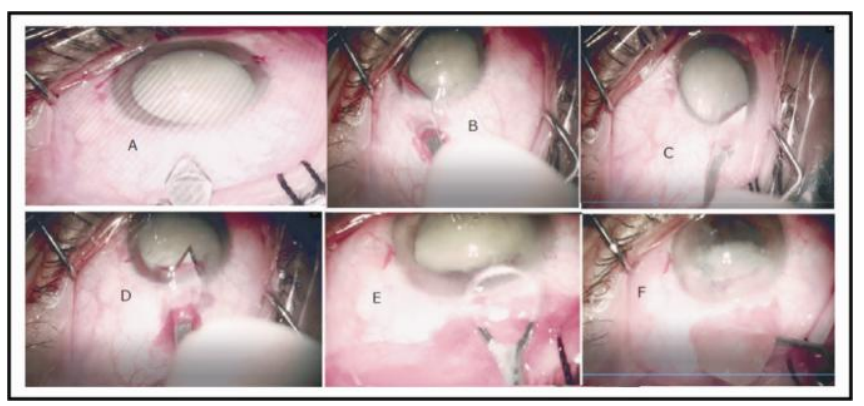

Figure 1(A): Entry into conjunctiva. (B, C): Tunnel construction with sweeping movement of Keratome. (D): Anterior chamber entry. (E, F): Nucleus delivery. 


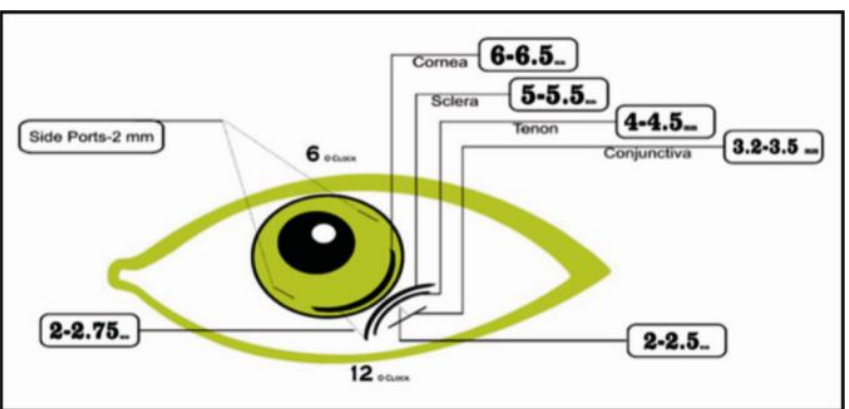

Figure 2: Diagram of the incision sites and sizes of modified technique.

\section{RESULTS}

Patients included in this audit cycle ranged from 50 to 85 years of age. In the first audit, one posterior capsular rupture occurred while polishing the posterior capsule. Anterior vitrectomy was done, IOL was placed in the sulcus and center of the main incision was sutured. Refractive and visual acuity data of 82 (82\%) patients who came for follow up after 1 week was analyzed. One out of three set standards achieved were (detailed in Table 1). Out of 9 patients who had 6/18 Snellen visual acuity, 2 had mild corneal edema (deep seated eyes), one had posterior capsular rupture during surgery, whereas surgically induced astigmatism (> 3D) was the cause in remaining 6 patients. One patient had age related macular degeneration (fundus not visible because of hypermature cataract during preoperative assessment) whose visual acuity was $6 / 36$ (Table2). Seven patients had large mature nuclei which required about $7 \mathrm{~mm}$ of scleral tunnel incision for delivery. These patients had $3 \mathrm{DC}$ or more of astigmatism post operatively.

Table 1: Comparison of the audit results with set standards.

\begin{tabular}{|c|c|c|c|}
\hline \multicolumn{4}{|c|}{ Results of the First Audit } \\
\hline Targets & Standard & Personal & Achieved \\
\hline $\begin{array}{l}\text { Posterior capsular } \\
\text { rupture }\end{array}$ & $1.4 \%$ & $1 \%$ & Yes \\
\hline $\begin{array}{l}\text { Corrected Visual acuity } \\
6 / 12 \text { or better }\end{array}$ & $89.2 \%$ & $85.36 \%$ & No \\
\hline Astigmatism of $<2 \mathrm{DC}$ & $85 \%$ & $75.60 \%$ & No \\
\hline \multicolumn{4}{|c|}{ Results of the Re-audit } \\
\hline Targets & Standard & Personal & Achieved \\
\hline $\begin{array}{l}\text { Posterior capsular } \\
\text { rupture }\end{array}$ & $1.4 \%$ & $0 \%$ & Yes \\
\hline $\begin{array}{l}\text { Corrected Visual acuity } \\
6 / 12 \text { or better }\end{array}$ & $89.2 \%$ & $90.50 \%$ & Yes \\
\hline Astigmatism of $<2 \mathrm{DC}$ & $85 \%$ & $87.05 \%$ & Yes \\
\hline
\end{tabular}

$(\mathrm{DC}=$ Diopter cylinder $)$

In the second audit (done after applying the modification) 85 (85\%) patients came for follow up after 1 week and data analysis revealed that all standards were achieved. Only one patient had visual acuity $<6 / 18$ because of asteroid hyalosis. Seven patients had $6 / 18$ visual acuity because of $>3 \mathrm{DC}$ astigmatism (4 patients), mild corneal edema (1 patient), and in 2 patients no obvious reason could be identified. Patients who had over 3 DC astigmatism required large scleral incision to deliver large nucleus. Results summarized in (table 2).

Table 2: Corrected visual acuity and surgically induced cylinder outcome of the first and second audit recorded on 7th postoperative day.

\begin{tabular}{|c|c|c|c|c|c|c|c|}
\hline \multicolumn{8}{|c|}{ Outcome of the First Audit } \\
\hline & & \multicolumn{3}{|c|}{ Corrected Visual Acuity } & \multicolumn{3}{|c|}{ Surgically Induced Cylinder } \\
\hline VA & $6 / 6-6 / 9$ & $6 / 12$ & $6 / 18$ & $<6 / 18$ & $<2 \mathrm{DC}$ & $2.5-3 \mathrm{DC}$ & $3.25-4 \mathrm{DC}$ \\
\hline Number of Patients & 57 & 13 & 9 & $1(6 / 36)$ & 62 & 13 & 7 \\
\hline Total & $(85.36 \%)$ & & $(10.97 \%)$ & $(1.21 \%)$ & $75.60 \%$ & $15.85 \%$ & $8.53 \%$ \\
\hline \multicolumn{8}{|c|}{ Outcome of the Re-audit } \\
\hline & \multicolumn{4}{|c|}{ Corrected Visual Acuity } & \multicolumn{3}{|c|}{ Surgically Induced Cylinder } \\
\hline VA & $6 / 6-6 / 9$ & $6 / 12$ & $6 / 18$ & $<6 / 18$ & $<2 \mathrm{DC}$ & $2.5-3 \mathrm{DC}$ & $3.25-4 \mathrm{DC}$ \\
\hline \#of Patients & 61 & 16 & 7 & $1(6 / 24)$ & 74 & 07 & 4 \\
\hline Total & $(90.50 \%)$ & & $(8.23 \%)$ & $(1.17 \%)$ & $87.05 \%$ & $8.23 \%$ & $4.70 \%$ \\
\hline
\end{tabular}

(VA=Visual acuity, DC=Diopter cylinder) 


\section{DISCUSSION}

In our re-audit of MSIC technique, clear improvement in surgical outcome in terms of best corrected visual acuity and surgically induced astigmatism were observed after modifying the technique. Reduction in surgically induced astigmatism has been observed by moving the incision from superior to superotemporal location in MICS in many studies. ${ }^{12,13}$ Different changes have been introduced in MICS technique since its introduction in terms of incision site, size and shape, tunnel length, number of side ports, their locations and purpose, methods of capsulorhexis and nucleus delivery to improve surgical outcome. Chevron's incision is reported to cause the least astigmatism compared to frown, straight and Blumenthal incisions. ${ }^{14}$ Moreover, farther the incision from the limbus and smaller in size, lesser the astigmatism. Side ports have been used for anterior chamber (AC) maneuvering and placement of $\mathrm{AC}$ maintainer. MSICS is better in terms of learning curve, surgical time, availability and affordability than phacoemulsification (gold standard) and has comparable results to it in terms of complication and long term visual outcome. Whereas, astigmatism is less and rehabilitation is faster in phacoemulsification.

Several guidelines have been established to improve the cataract surgery by using audit as a tool. According to Lindfield, it is important in clinical audit that if the initial results do not provide better results, further changes should be made for improvement. ${ }^{15}$ Thus, auditing and re-auditing is the key.

A standardized audit system for cataract surgeons is the EUREQUO project which helps cataract surgeons to monitor their results and compare them against a Europe-wide benchmark with the promise of improving the refractive results of cataract surgery. ${ }^{16}$

Retrospective manual auditing of cataract outcome is time consuming and many countries have adopted electronic system and it was recommended in the RCOphth's Cataract Surgery Guidelines. ${ }^{17}$ In Pakistan, we lack far behind in audit system. Few audits of cataract surgery are available but nonetheless, audit cycle is rarely carried out. ${ }^{18,19,20}$

Audit brings forth some interesting facts, which are generally overlooked. One study measured the number of times a sharp instruments was used in a modified MICS technique (all steps of the main incision and side ports were made with $3 \mathrm{~mm}$ keratome) in HIV patients and reported it to be 3 times (scissors for conjunctival peritomy, keratome for tunnel making and $25 \mathrm{G}$ needle for sub conjunctival medication), reducing the risk of transmission to a significant level. ${ }^{21}$

In terms of limitations, postoperative data after 1 week of surgery was analyzed because follow-up dropped to less than $50 \%$ on second week due to logistic and cultural reasons, whereas 4 to 6 weeks postoperative visual outcome data was reported in the literature from which the standards were developed. Secondly, all patients did not show up for follow up. These limitations may have affected the results, but lessons learned from this audit have improved the surgical outcome to a significant level.

\section{CONCLUSION}

This audit has shown that a superiotemporal sclerocorneal, wedge shaped tunnel incision (with 2 side ports 3 clock hours away from its center) has visual outcome and posterior capsular rupture rate comparable to the internationally accepted standards. Clinical audit is an effective tool to improve the outcomes of cataract surgery.

\section{ACKNOWLEDGEMENT}

Special thanks to British Pakistani Ophthalmic Society (BPOS) for review and to Mohammad Hassan Javed for helping with refractive data collection.

\section{Ethical Approval}

The study was approved by the Institutional review board/ Ethical review board. (SMO-1/LRBT)

\section{Conflict of Interest}

Authors declared no conflict of interest.

\section{REFERENCES}

1. Bowling B. Kanski's clinical ophthalmology: A systematic approach. 8th ed. London, England: W B Saunders; 2015.

2. Denniston A, Murray P. Oxford handbook of ophthalmology. London, England: Oxford University Press; 2018.

3. Vision impairment and blindness. Available at: http://www.who.int/mediacentre/factsheets/fs282/en/ 
4. Signes-Soler I, Javaloy J, Muñoz G, Moya T, Montalbán R, Albarrán C. Safety and Efficacy of the Transition from Extracapsular Cataract Extraction to Manual Small Incision Cataract Surgery in Prevention of Blindness Campaigns. Middle East Afr J Ophthalmol. 2016; 23 (2): 187-194.

Doi: 10.4103/0974-9233.175890.

5. Rajkarnikar S, Shrestha DB, Dhakal S, Shrestha R, Thapa K, Gurung A. Comparative Study of Extra Capsular Cataract Extraction (ECCE) and Small Incision Cataract Surgery (SICS): Experience on Cataract Surgery in a Tertiary Center of Army Hospital, Kathmandu. Nepal J Ophthalmol. 2018; 10 (20): 162167. Doi: 10.3126/nepjoph.

6. Limb C, Fowler A, Gundogan B, Koshy K, Agha R. How to conduct a clinical audit and quality improvement project. Int J Surg Oncol (N Y). 2017; 2 (6): e24. Doi: 10.1097/IJ9.0000000000000024.

7. Improvement Plan, Do, Study, Act (PDSA): NHS Institute for Innovation and Improvement, 2008. Available at: http://webarchive.nationalarchives.gov.uk/2012110807 4656/http://www.institute.nhs.uk/quality_and_service_i mprovement_tools/quality_and_service_improvement_t ools/plan_do_study_act.html.

8. Henry $\mathbf{P}$, Donachie J, Sparrow J. National Ophthalmology Database Audit. 2nd ed. [eBook] London: Royal College of Ophthalmologists London. https://www.nodaudit.org.uk/resources/publicationsannual-report

9. Venkatesh R, Muralikrishnan R, Balent LC, Prakash SK, Prajna NV. Outcomes of high volume cataract surgeries in a developing country. $\mathrm{Br} \mathbf{J}$ Ophthalmol. 2005; 89 (9): 1079-1083.

10. Bigyabati R, Victor R, Rajkumari B. A comparative study of the amount of astigmatism following conventional extra capsular cataract extraction and manual small incision cataract surgery. J Evid Based Med Health, 2016; 3 (47): 2342-2345.

Clinical audit. Available at:

http://www.uhbristol.nhs.uk/for-clinicians/clinicalaudit/

11. Nikose AS, Saha D, Laddha PM, Patil M. Surgically induced astigmatism after phacoemulsification by temporal clear corneal and superior clear corneal approach: a comparison. Clin Ophthalmol. 2018; 12: 65-70. https://doi.org/10.2147/OPTH.S149709

12. Sharma U, Sharma B, Kumar K, Kumar S. Evaluation of complications and visual outcome in various nucleus delivery techniques of manual small incision cataract surgery. Indian J Ophthalmol. 2019; 67 (7): 1073.

13. Singh K, Misbah A, Saluja P, Singh AK. Review of manual small-incision cataract surgery. Indian J Ophthalmol. 2017; 65 (12): 1281.
14. Lindfield R. The value of clinical audit to improve cataract quality. Community Eye Health, 2014; 27 (87): 55.

15. Improving refractive results of cataract surgery through audit. Available at:

https://crstodayeurope.com/articles/2011-

feb/improving-refractive-results-of-cataract-surgerythrough-audit/

16. The Royal College of Ophthalmologists. Cataract surgery guidelines, 2004.

http://www.rcophth.ac.uk/docs/publications/publishedguidelines/FinalVersionGuidelinesApril2007Updated.p df.

17. Chaudhry RK, Khan NQ, Dembra WK, Riaz A, Vickash G. Pediatric cataract surgery audit at a tertiary care center in Karachi, Pak. J. Ophthalmol. 2020; 36 (1): 38-42. https://doi.org/10.36351/pjo.v36i1.898.

18. Chhipa SA, Junejo MK. Outcomes of cataract surgery at teaching hospital in Karachi. J Pak Med Assoc. 2018; 68 (1): 76-80.

19. Paracha Q. Cataract surgery at Marie Adelaide Leprosy Centre Karachi: an audit. J Pak Med Assoc. 2011 Jul; 61 (7): 688-90. PMID: 22204247.

20. Giles K, Domngang C, Nguefack-Tsague G, Come EM, Wiedemann P. Modified Small Incision Cataract Surgery and Intraocular Lens Implantation in HIV Patients. Ophthalmol Eye Dis. 2015 Nov 9; 7: 35-7. Doi: $10.4137 /$ OED.S31013.

\section{Authors' Designation and Contribution}

Muhammad Ifraheem Khan; Fellow Pediatric: Concepts, Design, Literature search, Data acquisition, Data analysis, Manuscript preparation, Manuscript editing, Manuscript review.

Saba Ali Arif; Medical Officer: Concepts, Literature search, Data acquisition, Data analysis, Manuscript preparation, Manuscript review.

Muhammad Raja; Consultant Ophthalmologist: Concepts, Design, Data analysis, Manuscript preparation, Manuscript review.

Sheikh Ijaz; Consultant Ophthalmologist: Concepts, Design, Data analysis, Manuscript preparation, Manuscript editing, Manuscript review.

Muhammad Saeed Khan; Chief Medical Officer: Design, Literature search, Data acquisition, Data analysis, Statistical analysis, Manuscript preparation.

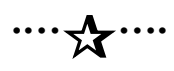

